

\title{
AMPLIANDO HORIZONTES EM PESQUISA QUALITATIVA NAS ORGANIZAÇÕES
}

Por:

Adriano de Lemos Alves Peixoto - University of Sheffield

RAE-eletrônica, v. 4, n. 2, Resenha 2, jul./dez. 2005

http://www.rae.com.br/eletronica/index.cfm?FuseAction=Artigo\&ID=3861\&Secao=RESENHAS \&Vol ume $=4 \&$ Numero $=2 \& A$ no $=2005$

CCopyright, 2005, RAE-eletrônica. Todos os direitos, inclusive de tradução, são reservados. É permitido citar parte de artigos sem autorização prévia desde que seja identificada a fonte. A reprodução total de artigos é proibida. Os artigos só devem ser usados para uso pessoal e nãocomercial. Em caso de dúvidas, consulte a redação: raeredacao@fgvsp.br.

A RAE-eletrônica é a revista on-line da FGV-EAESP, totalmente aberta e criada com o objetivo de agilizar a veiculação de trabalhos inéditos. Lançada em janeiro de 2002, com perfil acadêmico, é dedicada a professores, pesquisadores e estudantes. Para mais informações consulte o site www.rae.com.br/eletronica.

\section{RAE-eletrônica}

ISSN 1676-5648

C2005 Fundação Getulio Vargas - Escola de Administração

de Empresas de São Paulo.

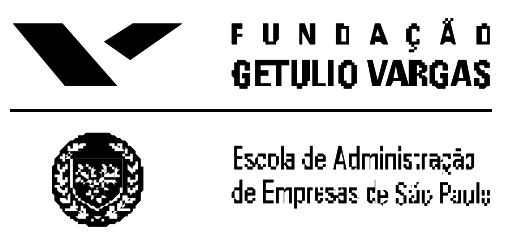




\title{
AMPLIANDO HORIZONTES EM PESQUISA QUALITATIVA NAS ORGANIZAÇÕES
}

Por:

\author{
Adriano de Lemos Alves Peixoto
}

Doutorando em Psicologia no Institute of Work Psychology, University of Sheffield - UK

E-mail: a.peixoto@sheffield.ac.uk

\author{
ESSENTIAL GUIDE TO QUALITATIVE METHODS IN ORGANIZATIONAL RESEARCH. \\ De Catherine Cassell e Gilian Simon (orgs.) \\ London: Sage Publications, 2004. 408 p.
}

Durante muitos anos o critério predominante de cientificidade para validação das pesquisas em ciências humanas ou sociais foi aquele oriundo dos campos ditos "duros" da ciência, ou seja, os utilizados nas disciplinas exatas, cujo principal objetivo sempre foi o de quantificar o fenômeno observado em suas múltiplas formas de expressão. Os resultados e os méritos desses procedimentos são inegáveis, bem como as conquistas originadas. Contudo, elementos significativos da expressão social e humana apresentam características e nuances que não podem ser totalmente apreendidas se o pesquisador se mantiver firmemente aferrado a um procedimento exclusivamente quantitativo. Nessa perspectiva é que se inscrevem os procedimentos qualitativos de pesquisa que, em um primeiro momento, afirmam sua identidade por meio da oposição aos procedimentos quantitativos.

Ainda que os métodos quantitativos de pesquisa possam ser definidos a partir de um paradigma funcionalista, positivista ou normativo, a pesquisa qualitativa, por sua vez, abrange uma diversidade de modelos, procedimentos, paradigmas epistemológicos e instâncias ontológicas que dificilmente podem ser abrigados sob o mesmo guarda-chuva conceitual. Portanto, a pesquisa qualitativa é extremamente diversificada e rica em seus fundamentos e procedimentos, não podendo ser adequadamente definida apenas em oposição aos procedimentos quantitativos. Ela é mais abrangente do que essa oposição permitiria supor.

Alguns fatores podem ser identificados quando se busca aprofundar o entendimento dessa relação entre pesquisa quantitativa e qualitativa, como, por exemplo, o fato de que existe muitas vezes, por parte dos pesquisadores, uma pressa em justificar seus métodos de pesquisa a partir de critérios normativos e inapropriados, provenientes dos procedimentos quantitativos, o que se constitui, na prática, em uma barreira à inovação. Um segundo fator que pode contribuir para a forma como essa relação se estabelece consiste na falta de treinamento adequado para pesquisadores em alternativa aos métodos tradicionais, aqui entendidos como aqueles da pesquisa quantitativa. Um terceiro elemento que pode ser identificado nessa relação engloba a identidade profissional, o avanço na carreira acadêmica e as relações institucionais de poder, seja no âmbito da academia, seja no âmbito das comunidades de práticas, que se constituem em componentes centrais na determinação das "boas práticas" de pesquisa. 
O problema que se coloca não é o da fraqueza ou do menor rigor da pesquisa qualitativa, mas saber o que significa uma "boa política" de pesquisa. Não se pode ignorar que a "boa política" é definida em um contexto político que é um elemento fundamental para o trabalho do pesquisador, e o Essential Guide foi escrito levando em conta esses elementos de contextualização política.

A pesquisa em organizações não escapa dessa situação. As organizações são objetos complexos que não podem ser reduzidos, em seu entendimento, pela onipotência metodológica. É nesse sentido que o Essential Guide traz uma contribuição fundamental para a compreensão e o processo de pesquisa qualitativa nas organizações. O livro tem como objetivo principal apresentar, a partir de uma tradição anglófona, uma série de técnicas relativas à pesquisa qualitativa. Ele se propõe ainda a difundir as técnicas qualitativas em um ambiente fortemente influenciado pela tradição quantitativa. Essa é uma obra voltada tanto para estudantes como para pesquisadores das áreas de Estudos Organizacionais, Administração e Gestão, e Psicologia Organizacional. Pela forma como foi elaborada, apresenta uma grande visão panorâmica de diversas técnicas, processos, estratégias e etapas da pesquisa qualitativa, estando dividida em 30 capítulos que abrangem diferentes formas de delineamento da pesquisa, passando tanto pelo levantamento e análise de dados quanto pela atitude do pesquisador com relação à pesquisa. Cada capítulo é escrito por um pesquisador com experiência específica no campo de atuação que se propõe apresentar, seja ele psicólogo organizacional, administrador ou sociólogo.

Os capítulos apresentam elementos descritivos das diversas práticas, bem como casos concretos de pesquisa em que esses métodos foram utilizados como forma de balizar o entendimento do leitor. Busca-se, ainda, definir os marcos epistemológicos e ontológicos que perpassam cada uma das técnicas apresentadas. Em função do número de capítulos, é possível perceber que a apresentação dos métodos e ténicas tem um caráter eminentemente introdutório, mas cada um deles apresenta uma indicação das leituras que permitem o aprofundamento do leitor.

$\mathrm{Na}$ introdução, as organizadoras apresentam o que entendem por pesquisa qualitativa e a orientação que fundamenta o trabalho. A proposta é divulgar métodos alternativos de pesquisa ao mainstream quantitativo da pesquisa organizacional, reconhecendo os elementos limitadores ao desenvolvimento da pesquisa e colaborando para influenciar a pesquisa na prática. Indicam os procedimentos a serem adotados pelos pesquisadores como forma de incrementar a consistência e a validade dos resultados da pesquisa qualitativa, o que demanda que se tenham critérios de avaliação dos resultados, reflexão sobre o processo da pesquisa e treinamento do pesquisador para dominar as técnicas.

Alguns dos procedimentos e técnicas apresentados são bem conhecidos, como as diferentes formas de entrevistas, as histórias de vida, os estudos de caso, as histórias nos contextos organizacionais, a observação participante e a etnografia. O livro apresenta contribuições significativas quando se distinguem as diversas perspectivas nas entrevistas, classificando-as como realistas, fenomenológicas e socioconstrucionistas, estabelecendo diferentes formas de aproximação e entendimento daquilo que diz o sujeito entrevistado a depender da perspectiva adotada. Outras técnicas, entretanto, são menos conhecidas e utilizadas, como o mapeamento cognitivo, a análise de sistemas suaves, a conferência futura, a técnica do incidente crítico, o grid de repertórios, a representação pictórica e o este das declarações. Já algumas das técnicas apresentadas são absolutamente novas, como é o caso dos questionários eletrônicos. Alguns capítulos seguem padrões mais técnicos sobre procedimentos de pesquisa, como o uso de modelos em análises temáticas de textos, o uso de matrizes de dados ou, ainda, as estratégias e métodos para o uso, compartilhamento e reutilização de dados de pesquisa qualitativa. 
É importante observar que muitas das técnicas apresentadas se afastam da tradição racional em pesquisa qualitativa. Nesse sentido, alguns leitores podem, inicialmente, sentir falta de referenciais teóricos para uma adequada avaliação da obra. Entretanto, isso é rapidame nte superado pela abertura de novos horizontes de investigação àqueles leitores interessados nas tramas da pesquisa.

Um dos marcos do livro é o cuidado com que explicita os pontos fortes de cada técnica, bem como suas limitações e finalidades. Os textos são construídos a partir da experiência prática de seus autores, o que se percebe em função da objetividade e dos exemplos utilizados. Porém nunca é demais lembrar que se trata de um livro introdutório, não devendo o leitor esperar mais do que um conjunto de marcos e especificações iniciais e uma relação de textos a seguir. Certamente falta profund idade teórica e conceitual em uma obra com esse formato.

O livro deve ser compreendido como um primeiro passo no processo de autodesenvolvimento na pesquisa qualitativa, recomendando-se como leitura introdutória por suprir uma lacuna na literatura disponível no país. Assim, o Essential Guide cumpre o que se propôs: ser um guia essencial para a prática da pesquisa qualitativa. 